\title{
A New Type of BTP/Zeolites Nanocomposites as Mixed-Phase Fire Suppressant: Preparation, Characterization and Extinguishing Mechanism Discussion
}

\author{
XIAOMIN NI, KAIQIAN KUANG, and GUANGXUAN LIAO \\ State Key Laboratory of Fire Science \\ University of Science and Technology of China \\ Anhui 230026, P. R. China
}

\begin{abstract}
A new type of nanocomposites consisting of solid 4A zeolites and gaseous fire extinguishing agent of 2bromo-3, 3, 3-trifluoropropene (BTP) was fabricated in large scale, in which BTP anchored in the porous zeolite nanoparticles. A series of techniques were used to characterize the composites, including X-ray diffraction (XRD), nuclear magnetic resonance (NMR), field-emission scanning electron microscopy (SEM), high-resolution transmission electron microscopy (HRTEM), Fourier transforms infrared (FTIR) spectra and thermogravimetric analysis (TGA). Laboratory-scale fire extinguishment tests showed that thus-prepared nanocomposites as additives can greatly improve the performance of conventional sodium bicarbonate $\left(\mathrm{NaHCO}_{3}\right)$ dry powder for relatively shorter extinguishing time and smaller amount of agents required. Such an improvement could be reasonably ascribed to the synergetic effect of solid $\mathrm{NaHCO}_{3}$ powder and the gaseous BTP desorbed from the zeolite host when presented to higher temperature, together with the porous zeolite as heterogeneous inhibition of flame free radicals. The possible fire extinguishing mechanism of the mixed phase powder-based suppressant was discussed in detail, which involved the simultaneous functions of three components of $\mathrm{NaHCO}_{3}$, BTP and zeolite.
\end{abstract}

KEYWORDS: zeolite, BTP, nanocomposite, suppression, synergetic effect

\section{NOMENCLATURE LISTING}

$\begin{array}{llll}g & \text { gram } & t & \text { time (s) } \\ T & \text { temperature (K) } & \mu m & \text { micron } \\ P & \text { pressure }(\mathrm{Pa}) & & \end{array}$

\section{INTRODUCTION}

Fire extinguishing powders have been paid much attention because of their advantages of high efficiency, low cost, environment-friendliness and wide applications in various fields [1-3]. For example, powders can be stuffed into handheld fire extinguishers and applied in areas short of water and high rise building with complicated systems $[4,5]$. The conventional fire suppressing agents such as sodium and potassium bicarbonates in powder form have been industrialized and employed in fire protection for many years. However, these fire suppressant powders usually have relatively large particle size $(10 \sim 75 \mu \mathrm{m})$, small surface area and short residence time in the flame, which resulted in unsatisfactory performance in fire suppression. In order to improve their efficiency, diversified methods have been explored which mainly focused on decreasing the particle size, blending heterogeneous dry chemical powders or mixing different phases fire suppression agents [6-8]. It has been well established that the efficiency of finely divided solids in extinguishing flame is a function of the particle size. With the particle size decreasing, the surface area of the particles and the suspending time of the particles in the flame would increase, which lead to a better fire suppressing effect. At present, decreasing the fire suppressant particle size is mainly through the techniques of ball milling or airslide disintegrating, which involve special equipments or complicated procedures. Another route of mixing heterogeneous chemical powders sometimes invalidates active components if chemical reactions occurred among the constituents. As for the mixed-phase fire suppression system, William Tarpley developed one using proprietary gelling agents to thixotropically suspend a monoammonium phosphate powder in a blend of halon 1211 and 1301 in the later 1960's [9]. With the discontinued vailability of halon in 1994, recently, Quantum Laboratories, Inc. exploits another mixed phase system based on heptafloropropane [8]. Although such blended systems could improve the efficiency of dry powder, however, a series of technical problems also emerged, such as modifying the chemistry of the powder and alter the physical design of the extinguisher to accommodate the characteristics of the new 
formula. Currently, it is still challenging to explore simple and effective methods to improve the performance of conventional powders in flame inhibition.

Zeolites are crystalline, microporous (alumino) silicates that have been extensively used in heterogeneous catalysis, adsorption, separations, and ion-exchange operations for their unique crystal structure and the microporous characteristics [10]. Especially, nanosized zeolite crystals have been of intensive interest for their high surface area and superior adsorption capacity [11]. In the commercial fire extinguishing powders, zeolite was an important ingredient, which was used to increase the fluid of the powder. Considering the excellent adsorption properties of nanozeolites to various ions or molecules, here, we envisaged to load a clean and efficient gaseous fire extinguishing agent of 2-bromo-3,3,3-trifluoropropene (BTP) into nanozeolites. Such gas-solid nanocomposites used as the additives to the commercial fire suppressant powders were found to greatly increase their effectiveness in fire inhibition, for the simultaneous functions of solid and gaseous chemicals that resulted in a synergy. The preparation, properties characterization and fire suppression mechanism of the composites particles were studied in detail. The present work finds a new way to improve the performance of solid fire extinguishing powders in virtue of the co-operative effect of the gaseous BTP, solid active $\mathrm{NaHCO}_{3}$ powder and porous zeolite particles.

\section{EXPERIMENTAL}

\section{Materials}

Laboratory grade Kaolin was used as the precursor for the preparation of zeolite. Analytical grade sodium hydroxide $(\mathrm{NaOH})$, liquid bromine $\left(\mathrm{Br}_{2}\right)$, potassium hydroxide $(\mathrm{KOH})$, ethanol $\left(\mathrm{C}_{2} \mathrm{H}_{5} \mathrm{OH}\right)$, 3,3,3trifluoropropene $\left(\mathrm{CF}_{3} \mathrm{CH}_{2} \mathrm{CH}_{2}\right)$ were purchased from Shanghai medicines Co. Ltd. The commercial fire extinguishing powder were sodium bicarbonate $\left(\mathrm{NaHCO}_{3}\right)$ dry chemical (BC Powder) available by Nan Jing Pu Xing Fire Extinction Agents Ltd.

\section{Sample Preparation}

Preparation of 4A zeolite crystals and 2-bromo-3,3,3-trifluoropropene (BTP) was according to the methods reported in reference 12-14, respectively [12-14]. A typical experiment for the preparation of BTP/zeolite composites was as following: $100 \mathrm{~g}$ dried zeolite powder and $100 \mathrm{ml} \mathrm{BTP} \mathrm{(in} \mathrm{beaker)} \mathrm{was} \mathrm{placed} \mathrm{in} \mathrm{a} \mathrm{glass}$ vessel, which was vacuumized at the temperature below $0^{\circ} \mathrm{C}$. Then the vessel was maintained at room temperature, in which BTP vapor were absorbed by zeolite powders. The vessel was placed quietly for $72 \mathrm{~h}$ until an absorption/desorption equilibrium was reached. Then zeolites with BTP molecules absorbed was collected and used for characterizations.

\section{Sample Characterizations}

X-ray diffraction (XRD) pattern of the sample was recorded on a Philips X'pert diffractometer with $\mathrm{Cu}$ $\mathrm{K} \alpha$ radiation $(\lambda=1.5418 \AA)$. The morphology and structure of the sample were studied with field emission scanning electron microscopy (FE-SEM, JEOL JSM-6700F) and high resolution transmission electron microscopy (HRTEM, JEOL-2010) with an accelerating voltage of $200 \mathrm{kV}$. Brunauer-Emmett-Teller (BET) nitrogen adsorption-desorption isotherms were researched on Accelerated Surface Area and Porosimetry System (ASAP $2020 \mathrm{M}+\mathrm{C}$ ). The nuclear magnetic resonance (NMR) spectra were collected from NMR spectromer (AVANCE AV 300). The Fourier transform infrared (FTIR) spectra of $\mathrm{KBr}$ wafers were recorded using a Bruker EQUINOX55 Fourier Transform Spectrometer. Thermogravimetry (TG) curves were acquired through the SHIMADZU DTG-60H instrument. Field emission spectra were collected by HR4000 high-resolution spectrometer and NIR256-2.5 extended-range NIR spectrometer.

\section{Fire Extinguishing Tests}

Two kinds of powder samples were used in the fire extinguishing experiments. Sample A is the commercial sodium bicarbonate dry chemical (BC Powder, Nan Jing Pu Xing Fire Extinction Agents Ltd). Sample B is the mixture of sample A and as-prepared BTP/zeolite composites (with the weight ratio of 9:1). The efficiency of suppressing pool fire by powder was investigated in a $1.0 \mathrm{~m}^{3}$ confined space. The details of the experimental apparatus are schematically shown in Figure 7a, which is consisted of a powder container with a nitrogen pressurized system, an oil pan and a data collection system. The powder container had an 
internal diameter of $63.5 \mathrm{~mm}$ and a height of $100 \mathrm{~mm}$. The brass cone-shaped powder nozzle has an internal diameter of $2.2 \mathrm{~mm}$ and a cone angle of $60^{\circ}$. Denatured alcohol was used as fuel, and the oil pan was $9 \mathrm{~cm}$ in diameter. K-type thermocouples were used to measure the flame temperature, which were located on a plank perpendicular to the pan with the spacing of $10 \mathrm{~cm}$ from the fuel surface. Before the experiment, a fixed amount of powder samples were added to the powder container and pressurized by nitrogen to a pre-assigned value. The powder was discharged after $35 \mathrm{~s}$ preburn time. The valve was turned off as soon as the fire was extinguished. The fire extinction time and the powder consumed were recorded.

Modified cup-burner was also used to foster a controlled and homogeneous flow of powder to study the extinction time and concentration of the two samples with the increasing of powder spraying rate $[15,16]$. The schematic diagram of the cup-burner equipped with a fluidized bed was shown in Figure $7 \mathrm{~b}$.

\section{RESULTS AND DISCUSSION}

\section{Structural Characterization of the BTP/zeolite composite}

XRD pattern of the zeolite sample was shown in Figure 1a. It was identical to that of the standard pattern of NaA zeolite (JCPDS Card: 14-90), revealing the 4A structure of our sample. No significant peak at $2 \theta=$ $20-30^{\circ}$, which was characteristic of amorphous phase were observed, indicating that a relatively high crystallinity of the sample. Compared with the pure zeolite, the composite did not show any obvious differences, indicating that the incorporation of BTP guest molecules did not change the crystalline structure of zeolite host. SEM images of Figure $2 \mathrm{a}$ and $2 \mathrm{~b}$ showed that thus-prepared zeolite consisted of cubic particles with the size of about $400-600 \mathrm{~nm}$. The surface area measured by BET nitrogen adsorptiondesorption isotherms (Figure 3) was estimated as $466.6 \mathrm{~m}^{2} / \mathrm{g}$, The pattern inset suggested the presence of micropores and mesorpores with two main pore size distributions at $4.0 \AA$ and $10 \AA$.

It was found that BTP/zeolite composite did not show obvious difference in crystal structure and morphology with that of pure zeolite. Compared with Figure 1a, XRD pattern of the composite (Figure 1b) exhibited nearly same diffraction peaks, indicating that the absorption of BTP hardly influenced on the crystal structure zeolite matrix. Also, SEM image of Figure 2c showed the similar shape and size characteristics of the composite with that of pure zeolite. Figure $2 \mathrm{~d}$ was a typical TEM image of several composite cubes, revealing the same morphological characteristics with the SEM images. Insets in Figure 2e were the corresponding selected area diffraction pattern (SAED) and lattice-resolved HRTEM image recorded on one cube, which indicate its crystalline structure. Such results further confirmed the structural and shape consistence of the zeolite before and after the absorption of BTP.

Figure 4 were the NMR spectra of as-prepared BTP and the BTP extracted from the composite using $\mathrm{CDCl}_{3}$ as extracting solvent. Both the spectra could be assigned to 2-bromo-3,3,3-trifluoropropene coexisting with trace of ethanol which originated from the raw materials. The similarity of the two spectra implied that BTP guest also kept same before and after being adsorbed into zeolite.

In order to prove the presence of BTP molecules in the zeolite particles, we compared the FTIR spectra of the zeolite before and after the BTP adsorption treatments. Figure 5 gave the FTIR spectra of pure zeolite (Figure 5a), BTP (Figure 5b) and the composite (Figure 5c) at room temperature. The absorption bands in Figure $4 \mathrm{a}$ agree well with the bands $\left(466,664,554\right.$, and $\left.1000 \mathrm{~cm}^{-1}\right)$ group of zeolite $4 \mathrm{~A}$ reported by Breck [10]. Three characteristic peaks 1282, 1185 and $1089 \mathrm{~cm}^{-1}$ could also be found in Figure $5 \mathrm{~b}$ and c and d. Careful observations indicated that the spectrum of the composite was the combination of Figure 5a and $b$, indicating that BTP molecules located in zeolite matrix. With the temperature increasing, the characteristic peaks of BTP in the composite gradually turn weaker, implying the desorption of BTP molecules from zeolite (Figure $5 \mathrm{~d}$ ). When the temperature increased to $300^{\circ} \mathrm{C}$, no peaks of BTP could be observed in the composites (Figure 5e), indicating the complete release of BTP.

From the TG curves of pure zeolite and BTP/zeolite composite shown in Figure 6, we could estimate the amount of BTP adsorbed into zeolite. In the temperature range of 30 to $700{ }^{\circ} \mathrm{C}$, a weight loss of $22.7 \%$ was observed in pure zeolite, which was possibly due to the water molecules remaining in zeolite matrix [17]. While a weight loss of $27.4 \%$ occurred in the composite. The higher weight loss could be ascribed to the BTP molecules absorbed in zeolite with the amount of about $4.8 \%$. At the temperature above $300^{\circ} \mathrm{C}$, the weight of the composite remained constant, indicating that all the BTP had desorbed from zeolite, which was consistent with the FTIR results. 


\section{Fire Suppression Tests}

A series of laboratory-scale extinguishing tests was carried out to assess the performance of the two samples of A and B in combatting ethanol pool fire. As shown in Table 1, the sample B containing 10 w.t. \% composites as additives obviously exhibited superior extinguishing performances to that of the single sodium bicarbonate dry powder. The average extinguishing time of sample B was $2.2 \mathrm{~s}$, while $5.4 \mathrm{~s}$ was needed for sample A under the same experimental conditions. Images at the different stages of the fire suppression process were shown in Figure 8. Meanwhile, it was found that the average amount of sample B powder consumed for extinguishing the fire was much decreased relative to that of sample A, keeping the discharging amount approximately equal. Taking that all the absorbed BTP released in the chamber, the BTP amount consumed in the fire suppression was much lowed than that of the single BTP used as the fire suppressant with the fire extinguishing concentration of $2.6 \%$ in flooding suppression [18]. Such results indicated that the blended powder requires substantially less total agent than either singe powder or gaseous system of the same fire suppression capacity.

Figure 9 presented the trends of flame temperatures of the above two experiments using different powder samples. A-D represented the temperatures at different heights above the liquid fuel. The temperature fluctuation of flame in the both figures was due to the unsteady bounding layer between the flame plume and the surrounding air. Temperature difference before and after adding powder obviously showed the suppressing effects of the powder ejected. It was demonstrated that sample B containing composites additives showed shorter extinguishing time than that of sample A without composite. Such a difference could be reasonably ascribed to the fire suppression effect of BTP, which possibly released from zeolite when presented to the flame with temperature higher than $300{ }^{\circ} \mathrm{C}$. Further proofs of the co-operative effect of BTP desorbed from zeolite were from the following flame emission spectroscopy observations.

Figure 10 gave the variations of the extinguishing time and the extinguishing concentration of the two samples with the powder spraying rates increasing, which were tested by a cup-burner. It further validated that the composite additives could effectively improve the performance of the sodium bicarbonate powder.

\section{Fire Suppression Mechanism Discussion}

The emission spectra of the flames suppressed by different chemicals gave more information of the cooperative effect from BTP and solid powder. Figure 11 was the spectrum of the flame suppressed by single $\mathrm{NaHCO}_{3}$ powder with the wavelength in the range of 200 to $1100 \mathrm{~nm}$. In the presence of conventional $\mathrm{NaHCO}_{3}$ powder, a sharp peak located at $590 \mathrm{~nm}$ was observed. For single BTP, only a large band at about $750 \mathrm{~nm}$ was shown. However, in the presence of BC powder with BTP/zeolite composite, the sharp peak at $590 \mathrm{~nm}$ and the band at $750 \mathrm{~nm}$ appeared simultaneously, implying the co-operative effect of BTP and BC powder. This result was in agreement with that of the above fire suppression effectiveness tests.

Successful fire suppression requires that one or more of the four factors of fuel, oxygen, heat and chain reaction which tend to propagate a fire be suppressed. A flame will be extinguished when the time required for the chain reaction which sustains combustion exceeds the time it takes to replenish the necessary heat and reactants [19]. The ratio (Damkohler number) of the characteristic flow time $\left(t_{\text {flow }}\right)$ to the characteristic chemical reaction time $\left(t_{\text {chem }}\right)$ was adopted to characterize the effectiveness of fire suppressing agents. The Damkohler number $\left(\mathrm{D}_{n}\right)$ can be formulated as:

$$
\mathrm{D}_{n}=\frac{t_{\text {flow }}}{t_{\text {chem }}}
$$

The Damkohler number criteria [20] suggests a number of methods for extinguishing fires that include increasing the strain rate or flame stretch (to decrease $t_{\text {flow }}$ ), or cooling, reactant removal, and chemical inhibition (to increase $t_{\text {chem }}$ ). The co-flow structure of powder and air flow in the cup-burner apparatus enhanced the interaction between powder and fuels, thus the strain rate or flame stretch would be increased. The flame blown off time obtained differed in different powder spraying rates. The influence of $t_{\text {chem }}$ caused by powders' composition, particle size distribution and microstructure is more concerned in our study. When the powder was sprayed to the fire, both thermal and chemical extinction effects were produced. Thermal mechanism means the vaporization of the powder particles as well as radiative energy transfer out of the flame. Most of the powder decompositions were endothermic, so the flame heat was removed by these reactions. The heterogeneous chemical mechanism was an effect of "thermal death" of free flame radicals (FFR) on a cold inert "wall" in essence. Unvaporized powders acted as a cold medium where 
recombination reactions (breaking combustion chain reaction) took place, each powder particle contributed to the destruction of FFR. Gaseous (homogeneous) reactions involved in alkali metal compounds comprised the main mechanism. Metal oxide (gas phase) reacted with water produced by decomposition, and the free radicals in the combustible chain reactions were scavenged by the gas phase metal radicals [21, 22].

In our tests, the new type of powder contained gaseous agents (BTP), stable porous additives (zeolites) and solid $\mathrm{NaHCO}_{3}$ powders, thus the two kinds of fire suppression mechanism (heterogeneous and homogeneous) contributing to the destruction of FFR were mutually related. The gaseous, homogeneous reactions for our conventional dry chemical in flame extinguishment could be formulated as following [23, 24]:

$\begin{array}{lll}2 \mathrm{NaHCO}_{3} \rightarrow \mathrm{Na}_{2} \mathrm{CO}_{3}+\mathrm{CO}_{2} \uparrow+\mathrm{H}_{2} \mathrm{O} \uparrow & \text { (2) } & \mathrm{Na}_{2} \mathrm{CO}_{3} \rightarrow \mathrm{Na}_{2} \mathrm{O}+\mathrm{CO}_{2} \uparrow \\ \mathrm{Na}_{2} \mathrm{O} \rightarrow \mathrm{Na}_{2} \mathrm{O} \uparrow & \text { (4) } & \mathrm{Na}_{2} \mathrm{O}+\mathrm{H}_{2} \mathrm{O} \rightarrow 2 \mathrm{NaOH} \\ \mathrm{NaOH}+\mathrm{H} \rightarrow \mathrm{Na}+\mathrm{H}_{2} \mathrm{O} & \text { (6) } & \mathrm{NaOH}+\mathrm{OH} \rightarrow \mathrm{NaO}+\mathrm{H}_{2} \mathrm{O}\end{array}$

On the other hand, BTP, one of the promising clean Halon replacers extinguished fire mainly as chemically active flame inhibitor that altered flame chemistry by catalytic recombination of key flame radicals, especially $\mathrm{H}$ and $\mathrm{O}$ atoms and $\mathrm{OH}$ radicals $[15,18]$. The fire suppression mechanism of BTP could be formulated as:

$$
\begin{aligned}
& \mathrm{CF}_{3} \mathrm{CBrCH}_{2} \rightarrow \mathrm{Br}+\mathrm{CF}_{3}+\mathrm{C}_{2} \mathrm{H}_{2} \\
& \mathrm{H}+\mathrm{HBr} \rightarrow \mathrm{Br}+\mathrm{H}_{2} \\
& \mathrm{CF}_{3}+\mathrm{O} \rightarrow \mathrm{CF}_{2} \mathrm{O}+\mathrm{F} \\
& \mathrm{CF}_{2}+\mathrm{H} \rightarrow \mathrm{CF}+\mathrm{FH} \\
& \mathrm{FCO}+\mathrm{OH} \rightarrow \mathrm{CO}_{2}+\mathrm{HF} \\
& \mathrm{F}+\mathrm{H} \rightarrow \mathrm{HF}
\end{aligned}
$$

$$
\begin{aligned}
& \mathrm{Br}+\mathrm{H} \rightarrow \mathrm{HBr} \\
& \mathrm{OH}+\mathrm{HBr} \rightarrow \mathrm{Br}+\mathrm{H}_{2} \mathrm{O} \\
& \mathrm{CF}_{3}+\mathrm{H} \rightarrow \mathrm{CF}_{2}+\mathrm{HF} \\
& \mathrm{FCO}+\mathrm{H}+\mathrm{M} \rightarrow \mathrm{F}+\mathrm{CO}+\mathrm{M} \\
& \mathrm{CF}+\mathrm{OH} \rightarrow \mathrm{HF}+\mathrm{CO}
\end{aligned}
$$

The former results have confirmed that the loading of BTP molecules into porous zeolite not only provided place to store BTP, but also improved the performance of dry powders as powder additives. It was assumed that the nano-size porous zeolite absorbed with BTP gases, which were surrounded with BC powder, acted as a key "reaction wall" or "FFR sink" in fire suppression. With the help of zeolite, the absorbed BTP were easy to reach the flame zone, desorbed and evaporated at higher temperatures. The homogeneous inhibition of FFR listed in formula 8-18 occurred and accelerated in the porous "reaction sink".

The first affecting factor was considered the particle size or the "cloud density" of powder. According to previous reports, mass powder particles can act as a wall or window effect to extinguish fire $[25,26]$. Krasnyansky considered powder cloud as a three-dimensional grid "put" on a flame. The mechanism of flame suppression consists in fast thermal destruction (or recombination) of FFRs due to their collision with a surface of particle grid elements. The three-dimensional powder particles become an "inert wall", which absorbs part of FFRs energy. Then, it is obvious that what we called "grid" size or powder particles distance between each other is the key factor to fire extinguishing. Each powder particle in such a "cloud" will contribute to better FFR destruction around itself when the wall or cloud is compact and dense [27]. Since that the effectiveness of any of these agents depends on the particle size, the smaller the particles, the fewer agents are needed as long as particles are larger than a critical size. The particle size shown in Figure 2 was smaller than $1 \mu \mathrm{m}$, therefore, when powder was being sprayed to the flame in a mist, the particles were easily distributed and suspended in the hot air around the flame, and the quantity of FFRs decreased rapidly.

The porous structure and large surface area of powder particles facilitated the homogeneous and heterogeneous inhibition. In the absorption process and chain interruption reaction described by Krasnyansky [25], the importance of surface defects which were the centres of adsorption was introduced. And the influence of heterogeneous inhibition for fire extinguishing powders depended on some factors such as surface adsorption properties degree of surface, etc. The new type of powder additive with unique porous structure and nanosize contributed to a "perfect" surface defects for flame extinction, facilitating the capturing of FFR. The possible chain reactions involved the flame radicals absorbed in the porous zeolite after the desorption of BTP molecules were shown as formula 19-24:

$\mathrm{O}_{\mathrm{ads}}+\mathrm{O}_{\mathrm{gas}} \rightarrow \mathrm{O}_{2}$
$\mathrm{H}$

$$
\begin{aligned}
\mathrm{H}_{\text {ads }}+\mathrm{O}_{2 \text { (gas) }} & \rightarrow \mathrm{HO}_{2} \\
\mathrm{H}_{\text {ads }}+\mathrm{O}_{\text {gas }} & \rightarrow \mathrm{OH}
\end{aligned}
$$


$\mathrm{O}_{\text {ads }}+\mathrm{H}_{\mathrm{gas}} \rightarrow \mathrm{OH}$

$$
\mathrm{O}_{\text {ads }}+\mathrm{H}_{2 \text { (gas) }} \rightarrow \mathrm{H}_{2} \mathrm{O}
$$

Based on above discussion, three roles of BTP, $\mathrm{NaHCO}_{3}$ and porous zeolites were believed simultaneously to contribute to the inhibition of FFR. The possible mechanism of the dry powder containing BTP/zeolite composites was schematically demonstrated in Figure 12. But the detailed mechanism is still obscure and the further research is in progress.

\section{CONCLUSIONS}

A new type of fire suppressant additives consisting of gaseous 2-bromo-3, 3, 3-trifluoropropene (BTP) and solid zeolite particles was created in virtue of the superior adsorbing capacity of porous zeolite. A series of techniques of XRD, SEM, FTIR, NMR and TG indicated that BTP molecules were loaded in the zeolite matrix. Laboratory-scale experiments of fire suppression effectiveness indicated that the composite as additives can greatly increased the performance of the common dry powders by decreasing the extinguishing time and the amount of the powder consumed. Such an improvement of fire suppression performance could be ascribed to the synergetic effect of BTP desorbed from zeolite hosts when presented to high temperatures, solid sodium bicarbonate powder and porous nanosized zeolite heterogeneously capturing the flame free radicals. The combination of BTP and zeolite not only increased the fire suppression efficiency of dry powder, but also provide storage for gaseous fire suppressants, which combined of two kinds of fire extinguishing agents together. Our work presented a new idea to improve the effectiveness of dry powder by introducing another gaseous suppressant into the powders matrix, which showed advantages of simplicity, high efficiency, low-cost and hardly any influence on the current chemistry of powder and physical designs of the extinguisher. The further investigations on the effect of delayed the agent application and scale up to larger fires both in compartments and in the open and the effectiveness on different fuels are in progress.

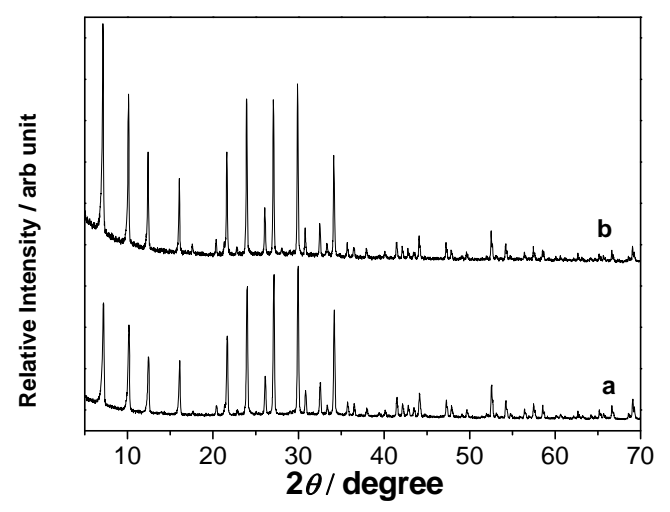

Fig. 1. XRD patterns of the zeolite (a) and BTP/zeolite (b) composite

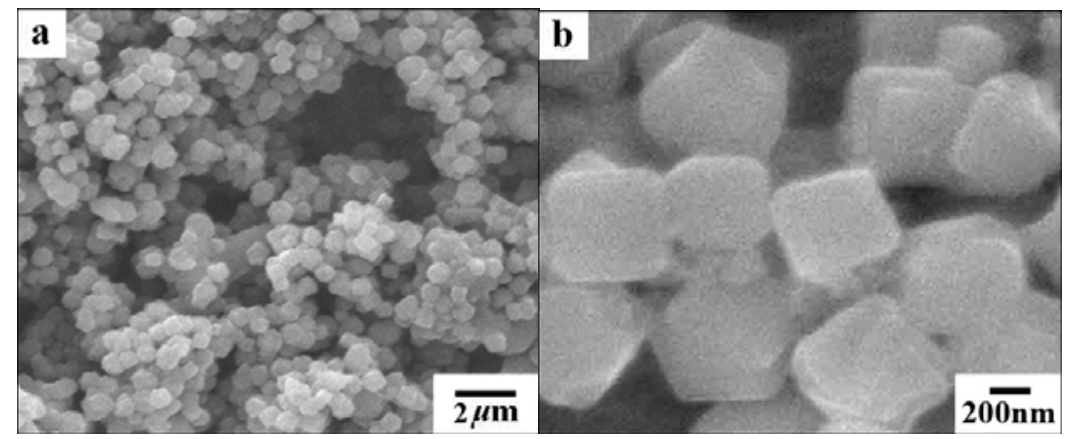




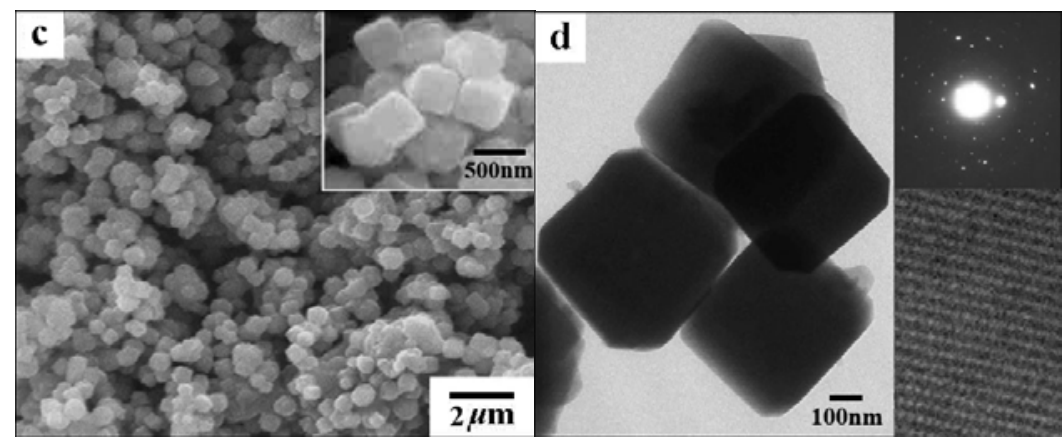

Fig. 2. (a) panoramic and (b) magnified SEM image of the zeolite particles. (c) SEM images of the composite particles. (d) TEM image of several composite particles. (e) A typical HRTEM image of the cube shown in (d).

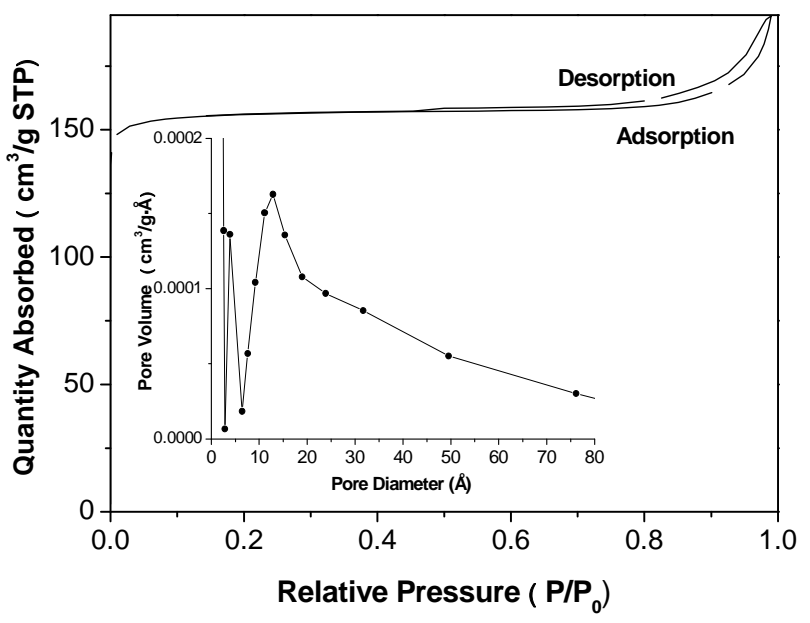

Fig. 3. Nitrogen adsorption-desorption isotherms for as-prepared zeolite, inset was the corresponding pore size distribution.

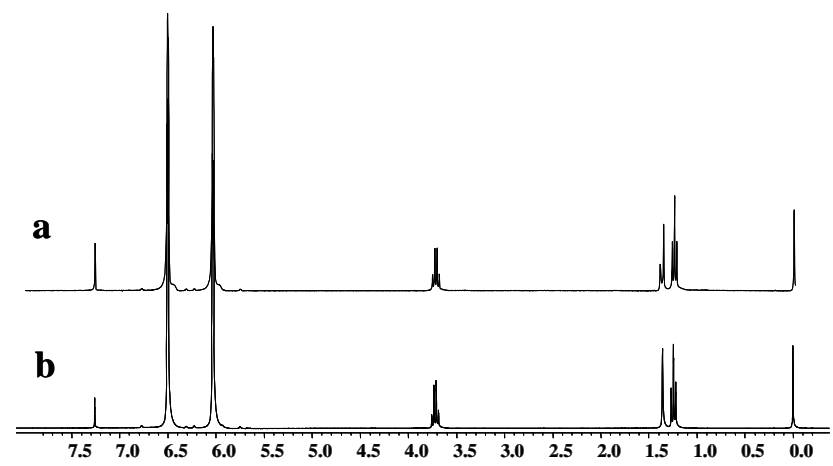

Fig. 4. NMR spectra of the raw material of BTP (a) and BTP extracted from the composite with $\mathrm{CDCl}_{3}$ as extraction solvent (b). 


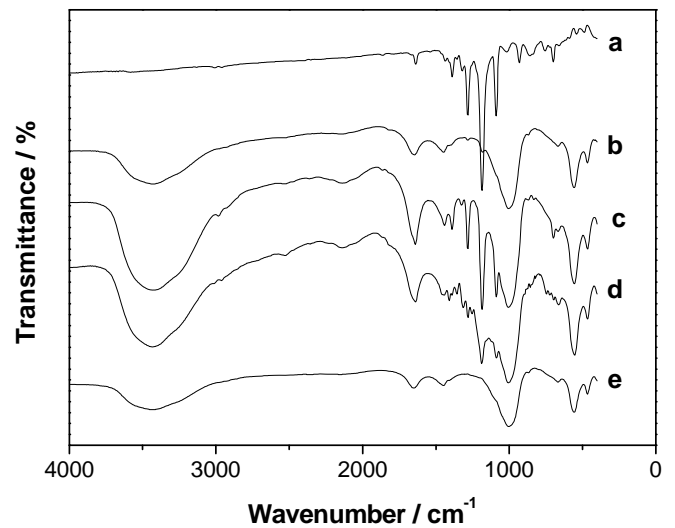

Fig. 5. FTIR spectra of the pure BTP(a), zeolite (b) and BTP/zeolite composites (c) at room temperature. (d) composites at $200{ }^{\circ} \mathrm{C}$. (e) composites at $300{ }^{\circ} \mathrm{C}$.

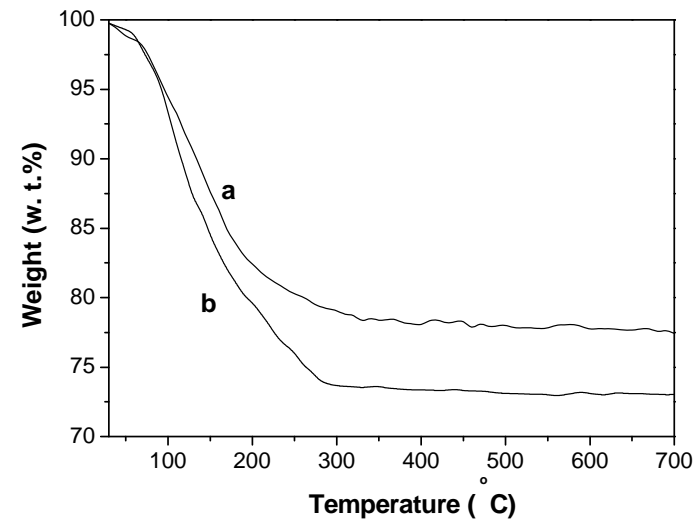

Fig. 6. TG curves of pure zeolite (a) and BTP/zeolite composite (b).

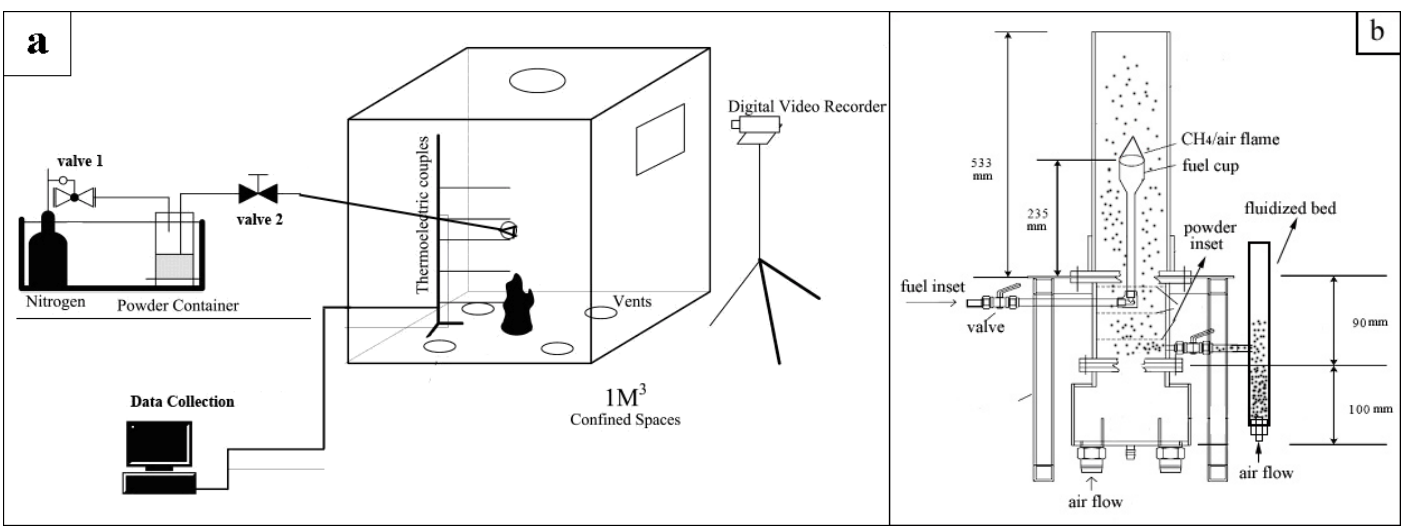

Fig. 7. Schematic illustration of the laboratory-scale apparatus for fire extinguishing tests (a) and the cupburner (b) 


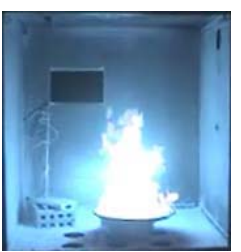

$0 \mathrm{~s}$

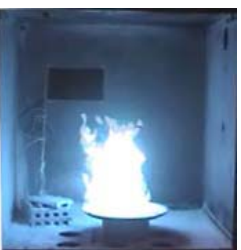

$0 \mathrm{~s}$

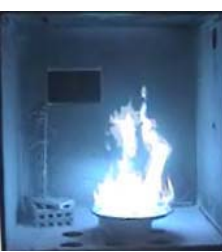

$1.0 \mathrm{~s}$

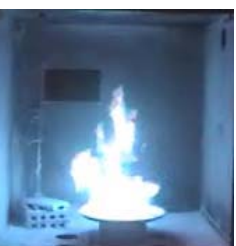

$0.5 \mathrm{~s}$

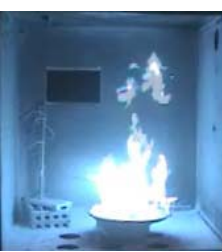

$3.0 \mathrm{~s}$

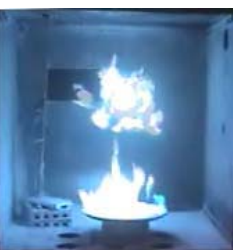

$1.0 \mathrm{~s}$

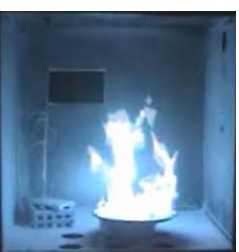

$4.0 \mathrm{~s}$

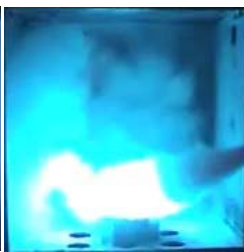

$1.5 \mathrm{~s}$

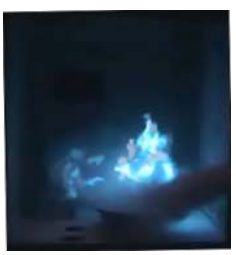

$4.5 \mathrm{~s}$

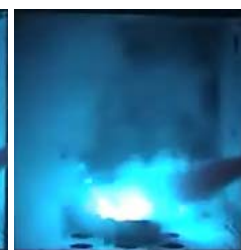

$2.0 \mathrm{~s}$

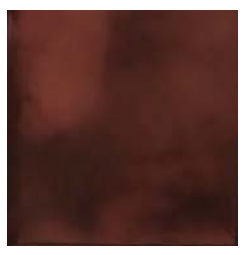

$5.4 \mathrm{~s}$

Fig. 8. Images of the flame at different stages after the powder was ejected into the chamber (a) sample A, (b) sample B.
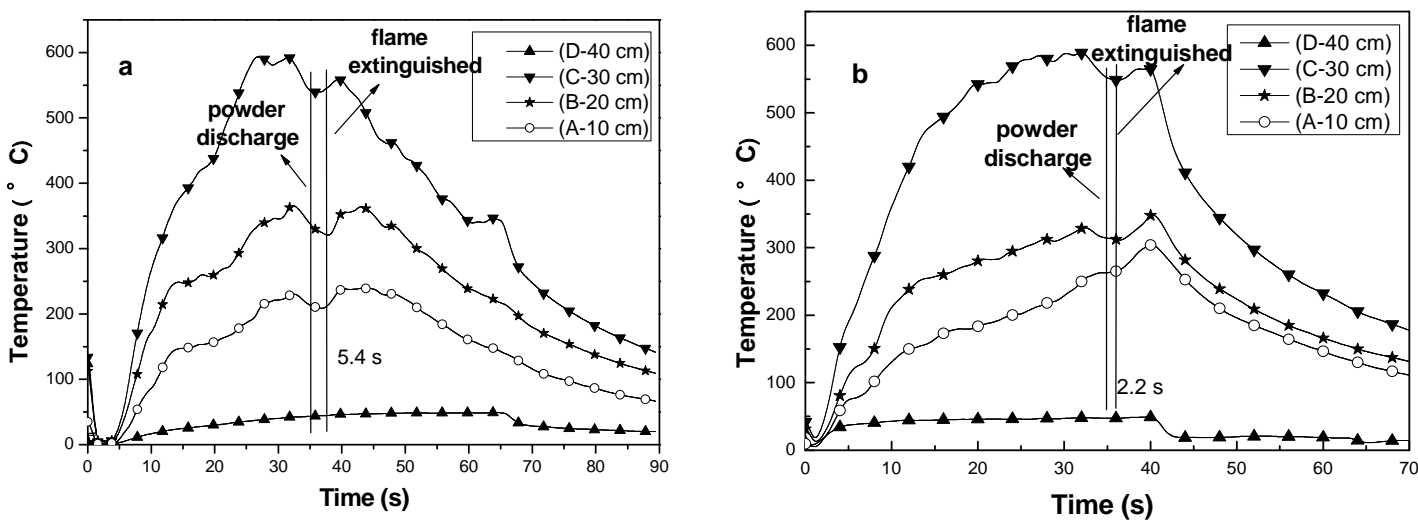

Fig. 9. The flame temperature variations of two contrast experiments using different fire extinguishing agent sample. (a) sample A, (b) sample B.
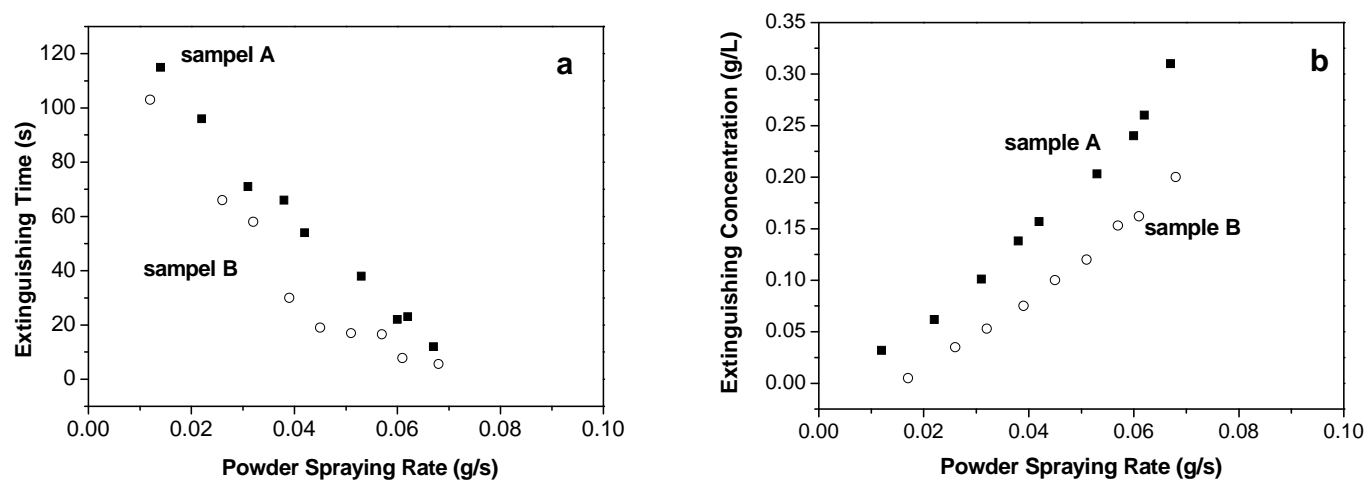

Fig. 10. The curve of the extinguishing time (a) and extinguishing concentrations (b) varying with the powder spraying rate of the two samples. 


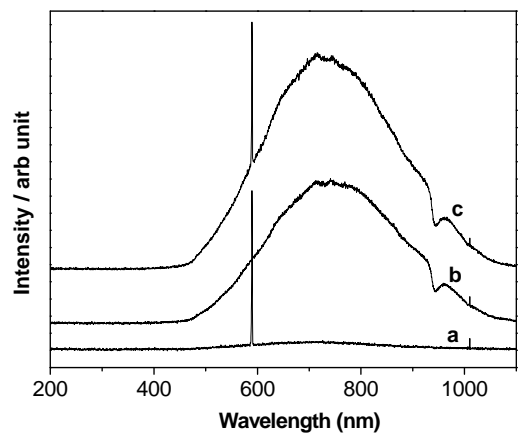

Fig. 11. The flame emission spectra of the methane/air flame suppressed by different fire suppressants. (a) commercial $\mathrm{NaHCO}_{3}$ powder, (b) BTP, (c) commercial BC powder containing BTP/zeolite composite additives (with $10 \%$ weight ratio).

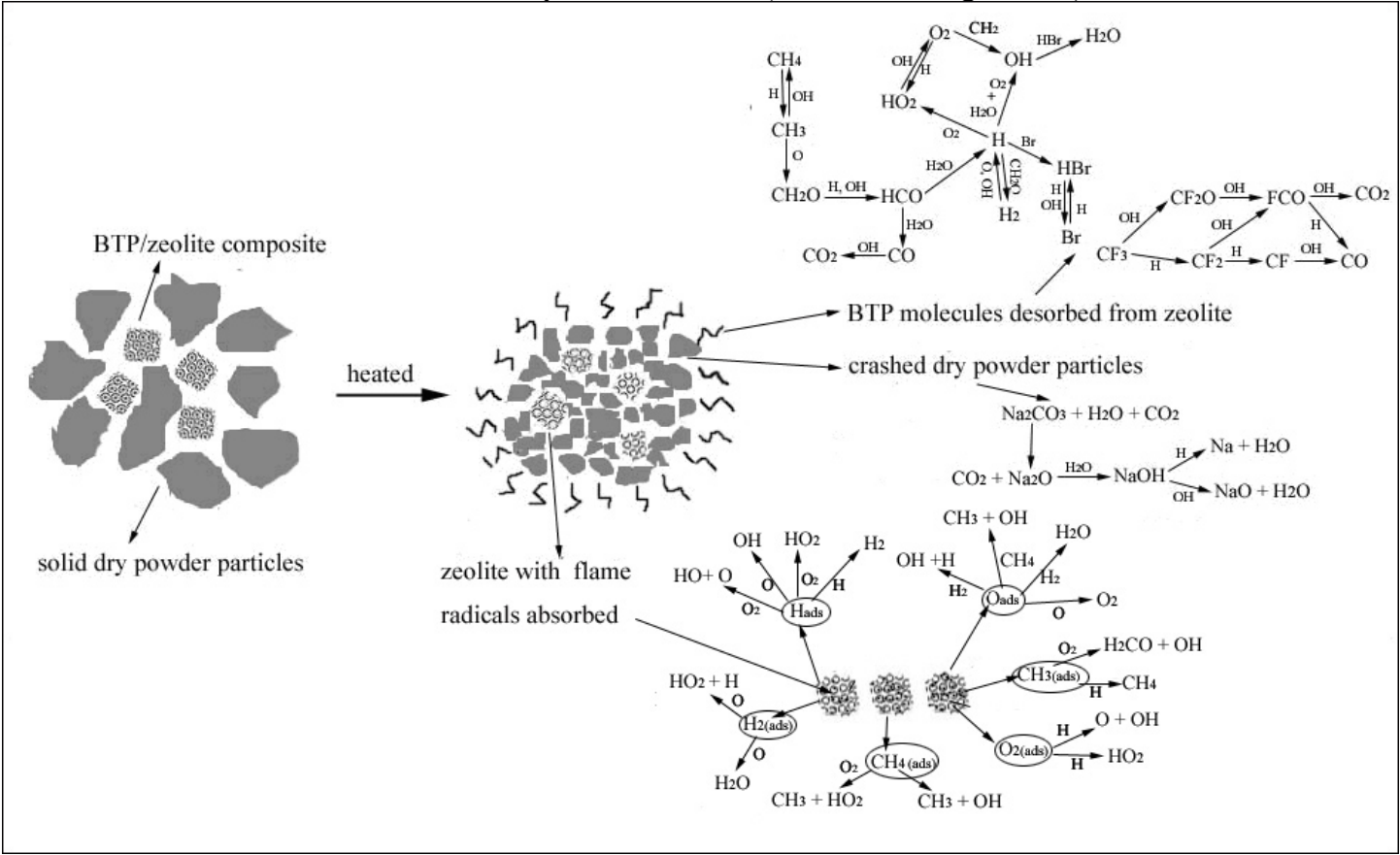

Fig. 12. The schematic illustration of the possible fire suppression mechanism in capturing the free flame radicals of the $\mathrm{NaHCO}_{3}$ based dry powder with $\mathrm{BTP} /$ zeolite composite as additives.

Table 1. Fire extinguishing time and the weight of the samples consumed.

\begin{tabular}{|c|c||c|}
\hline Samples & Fire extinguishing time & weight of the powder consumed \\
\hline Sample A & $5.4 \mathrm{~s}$ & $36.6 \mathrm{~g}$ \\
\hline \hline Sample B & $2.2 \mathrm{~s}$ & $12.5 \mathrm{~g}$ \\
\hline
\end{tabular}

\section{REFERENCES}

[1] Gann, R. G., “A Millennial View of Fire Suppression”, Halon Options Technical Working Conference (HOTWC). 2000. Gaithersburg, MD: NIST SP 984, National Institute of Standards and Technology. 
[2] Dricker, G. Y., "New Fire Extinguishing Agents in Russia in the 1990s" Halon Options Technical Working Conference (HOTWC). 2000, NIST SP 984, National Institute of Standards and Technology: Gaithersburg, MD.

[3] Spring, D. J., and Ball, D. N., "Alkali Metal Salt Aerosols as fire Extinguishants", Halon Options Technical Working Conference (HOTWC). 2003. Gaithersburg, MD: NIST SP 984, National Institute of Standards and Technology.

[4] Like, J., Moore, T. A., and Mather, J. D., "Handheld Fire Extinguisher Development", Halon Options Technical Working Conference (HOTWC). 2000. Gaithersburg, MD: NIST SP 984, National Institute of Standards and Technology.

[5] Brooks, J., Berezovsky, J., and Dwyer, M. O., "Aerosol Fire Suppression for High Rise Structural Applications via Aircraft Distribution using Metalstorm technologies", Halon Options Technical Working Conference (HOTWC). 2002. Albuquerque, NM: NIST SP 984, National Institute of Standards and Technology.

[6] Birchall, J. D., "On the Mechanism of Flame Inhibitation by Alkali Metal Salts", Combusting and Flame, 1970, 14, 85-96. doi:10.1016/S0010-2180(70)80013-X

[7] Anatoly, B., Iousef, M., Yechiel, S., and Esther, J., "Fire Extinguishing Methods and Systems", US Patents, 5423385.

[8] McHale, B. G., "Mixed Phase Fire Suppression Systems: Application and Benefits" Halon Options Technical Working Conference (HOTWC). 2002. Albuquerque, NM: NIST SP 984, National Institute of Standards and Technology.

[9] Tarpley, Jr., William B., Ruscitto, and Gerald, L., "Vinyl Polymer Gelling Agent for Powder Dissemination Composition" US Patent 4652383

[10] Breck, D. W., "Zeolite Molecular Sieves: Structure, Chemistry and Use”; Wiley: New York, 1974.

[11] Vuong, G. T., and Do, T. O., (2007) “A New Route for the Synthesis of Uniform Nanozeolites with Hydrophobic External Surface in Organic Solvent Medium" Journal of American Chemical Society 129: 3810-3811. doi:10.1021/ja069058p

[12] Park, J., Kim, B. C., Park, S. S., and Park, H.C., (2001) "Conventional versus Ultrasonic Synthesis of Zeolite 4A from Kaolin", Journal of Materials Science Letters 20: 531-533. doi:10.1023/A:1010976416414

[13] Yotsuya, T., Seki, K., Awano, Y., and Kubo, M., Japan Potent, 200169404, 2000-6-20.

[14] Mori, M., Japan Potent, 2001322955, 2001-11-20.

[15] Zhang, Y. F., Lin, L., Jin, X., Huang, X., and Liao, G. X., (2007) "Fire-extinguishing Effectiveness of 1-Bromo-3,3,3-Trifluoropropene/Inert Gaseous Mixture Evaluated by Cup Burner Method", Process Safety and Environmental Protection 85: 147-152, doi:10.1205/psep06010

[16] Hamins, A., "Flame Extinction by Sodium Bicarbonate Powder in a Cup-Burner" Combustion Insititute, Symposium (International) On Combustion, 27th, Proceedings, Volume 2, August 2-7, 1998, Boulder, CO, Combustion, Institute, Pittsburgh, PA. 1998, pp 2857-2864,

[17] Lee, H. J., Kim, Y. M., Kweon, O. S., and Kim, I. J., (2007) "Structural and Morphological transformation of $\mathrm{NaX}$ zeolite crystals at high temperature", Journal of European Ceramic Society 27: 561-564. doi:10.1016/j.jeurceramsoc.2006.04.156

[18] Tapscott, R. E., Sheinson, R. S., Babushok, V., Nyden, M. R., and Gann, R. G., "Alternative Fire Suppressant Chemicals: A Research Review with Recommendations", NIST Technical Note 1443.

[19] Pitts, W. M., Yang, J. C., Gmurczyk, G., Cooper, L.Y., and Grosshandler, W. L., Cleveland, W.G. and Presser, C., Chapter 3. Fluid dynamics of agent discharge. In: Grosshandler, W. L., Gann, R.G., and Pitts, W. M., Editors, Evaluation of Alternative In-Flight Fire Suppressants for Full- 
Scale Testing in Simulated Aircraft Engine Nacelles and Dry Bays, U.S. Department of commerce, Washington, DC, April 1994, NIST Special Publication 861.

[20] Liiian, A., (1974) "The Asymptotic Structure of Counterflow Diffusion Flames for Large Activation Energies", Acta Astronautics 1: 1007. doi:10.1016/0094-5765(74)90066-6

[21] Ewing, C.T., Faith, F. R., Hughes, J. T., and Carhart, H. W., (1989) "Flame Extinguishment Properties of Dry Chemicals: Extinction Concentrations for Small Diffusion Pan Fires", Fire Technology 25: 133-149. doi:10.1007/BF01041422

[22] Williams, B. A., and Fleming, J. W., "Suppression Mechanisms of Alkali Metal Compounds" Halon Options Technical Working Conference, April 1999, p. 27-29.

[23] Birchall, J. D., (1970) "On the Mechanism of Flame Inhibition by Alkali Metal Salts", Combustion and Flame 14: 85-95. doi:10.1016/S0010-2180(70)80013-X

[24] Jensen, D. E. and Jones, G. A., (1982) "Kinetics of Flame Inhibition by Sodium", J. Chem. Soc. Faraday Trans. 78: 2843-2850. doi:10.1039/f19827802843

[25] Krasnyansky, M. "Studies of Fundamental Physical-Chemical Mechanisms and Processes of Flame Extinguishing by Powder Aerosols" Fire and Materials, 2007. in Press.

[26] Bennett J. M., “ "Black widow” Thermal Absorptivity-Enhanced Dry Chemical Powder - Recent Evaluations in Various Fire Protection Applications", Halon Options Technical Working Conference (HOTWC). 2006, NIST SP 984, National Institute of Standards and Technology: Albuquerque, NM.

[27] Friedman, R., Principles of Fire Protection Chemistry (2 ${ }^{\text {nd }}$ Edition), National Fire Protection Association, 1989; p 190-192. 